\title{
Patient competence in the context of cancer: its dimensions and their relationships with coping, coping self-efficacy, fear of progression, and depression
}

\author{
Jürgen M. Giesler ${ }^{1}$ (D) Joachim Weis ${ }^{2}$ \\ Received: 27 May 2020 / Accepted: 19 August 2020 / Published online: 2 September 2020 \\ (C) The Author(s) 2020
}

\begin{abstract}
Purpose Influenced in part by research on coping, patient empowerment and self-efficacy, and by patient self-help initiatives, the construct of patient competencies (PC) has been elaborated and later integrated into Germany's National Cancer Plan. As a selfreport measure of PC, the Patient Competence Questionnaire 57 (PCQ-57) has only rarely been evaluated psychometrically. Therefore, we aimed to re-examine its dimensionality and its relationships with related constructs and potential psychosocial cancer outcomes.

Methods We surveyed 424 breast, colorectal, and prostate cancer patients from clinics for oncological rehabilitation and private oncology practices who completed the PCQ-57 and self-report measures of coping, coping self-efficacy, fear of progression, and depression. Patients' PCQ-57 responses were submitted to principal axis factor analyses. Using the original scoring keys, we computed internal consistencies (Cronbach's $\alpha$ ) and Pearson correlations between all measures.

Results Factor analyses suggested 5 of the 8 original PCQ- 57 dimensions to replicate satisfactorily, their internal consistencies ranging from 0.74 to 0.88 . The competency of managing distress correlated significantly, highly, and negatively with fear of progression and depression $\left(\left|r^{\prime} s\right| \geq 0.43\right)$ and positively with coping self-efficacy $(r=0.58)$.

Conclusion The results support the reliability and validity of 5 of the 8 original PCQ-57 scales while suggesting refinement of the others. The replicated scales may help identify patients in need of support for dealing with the multiple tasks of adjusting to cancer. Further research should clarify the conceptual and empirical relationships between PC, health literacy, and patient activation as well as potential effects of PC on psychosocial cancer outcomes.
\end{abstract}

Keywords Cancer $\cdot$ Patient competence $\cdot$ Coping $\cdot$ Self-efficacy $\cdot$ Fear of progression $\cdot$ Depression

\section{Introduction}

During the course of its development as a scientific discipline [1], central goals of psycho-oncology have by now come to include supporting cancer patients as well as their family and friends

Electronic supplementary material The online version of this article (https://doi.org/10.1007/s00520-020-05699-0) contains supplementary material, which is available to authorized users.

Jürgen M. Giesler

juergen.giesler@uniklinik-freiburg.de

1 Section of Health Care Research and Rehabilitation Research, University of Freiburg Medical Center, Hugstetter Str. 49, D

79106 Freiburg, Germany

2 Comprehensive Cancer Center, Department of Self-Help Research, University of Freiburg Medical Center, Freiburg, Germany through research and practice in their efforts to cope with distressing emotions associated with the diagnosis of cancer [2-5], to decide on treatment options [6-8] and to manage long-time sequelae during survivorship $[9,10]$. In order to conceptualize the patient's personal resources to meet these challenges, a variety of more general concepts are available like self-efficacy [11, 12], empowerment [13-16], patient activation $[17,18]$, and health literacy [19-22]. Tied more specifically to the context of cancer, the construct of patient competence (PC) has been developed on the basis of conceptual and empirical analyses [23-27] and later been integrated into Germany's National Cancer Plan, specifying the aim of advancing PC, thus contributing to the plan's overall goal of enhancing patientcentered cancer care [28]. In terms of a working definition, PC has been defined as a cancer patient's ability to manage emotionand problem-focused coping tasks [29, 30] arising throughout the cancer trajectory [23]. This focus on abilities links PC with 
the concept of self-efficacy defined as confidence in being able to perform specific behaviors, while distinguishing it from coping which traditionally focuses on factual (past or present) behaviors aimed at managing specific task and emotion-focused challenges of one's cancer. As a multidimensional measure of PCs, the Patient Competence Questionnaire 57 (PCQ-57) has been developed with the intention to enable research on potential effects of PC on patient-reported cancer outcomes and to determine possible effects of intervention programs aimed at promoting PCs in cancer patients [23].

Although the PCQ-57 has been used as an outcome in several intervention studies [31-33], albeit showing no effect, however, information on its construct validity and reliability has never again been provided since the initial study that had reported acceptable to good internal consistencies for its scales and small to medium correlations with global health status as an indicator of quality of life [23]. In addition, the relationship of PC with conceptually related constructs and potential psychosocial cancer outcomes has not been examined thus far. Given the working definition of PC, it should therefore be especially informative to explore relationships between PC and apparently related resource constructs like cancer patients' use of coping behaviors or their self-efficacy beliefs with respect to coping with cancer $[11,12]$. Since PC may also be expected to help cancer patients manage distressing emotions, it would also be interesting to learn how PC relates to, e.g., fear of progression or depression as frequent comorbid conditions of cancer that continue to attract the interest of researchers $[3,4,34,35]$. Such relationships would underline that PC could fruitfully be linked to concepts of self-regulation of action and emotion [12, 30, 36].

Therefore, this study intended:

a) To re-examine the factor structure of the PCQ-57 and its internal consistency reliability

b) To analyze its validity with respect to coping and coping self-efficacy and to fear of progression and depression.

The study was part of a larger project that additionally asked, by employing a longitudinal design with 3 measurement points (baseline, 4 weeks and 10 months post baseline), whether PC differed between patients with different types of cancer and whether it changed across time. Results from these analyses will be reported elsewhere. The present analyses are based on the baseline data from the project.

\section{Methods}

\section{Participants and procedure}

In line with the research questions above, participants were recruited in seven clinics for oncological rehabilitation $(n=$
$377)$ and three private oncology practices $(n=47)$. Rehabilitation clinics were chosen, because they aim at improving physical and psychological functioning, coping with illness, self-management, and participation [37]. Oncology practices were included to ascertain recruitment of a sufficiently large number of patients under palliative treatment. To cover the most frequent tumor entities, we chose to include patients with either breast or prostate cancer. In addition, we included colorectal cancer patients to represent a tumor entity that shows a roughly comparable incidence between the sexes. Patients treated with either curative or palliative intent were both eligible for the study. Furthermore, participants were to be at least 18 years old, sufficiently fluent in German and willing to participate in a questionnaire study. Patients with acute and severe psychiatric disorders (e.g., acute psychosis) or severe cognitive impairment impeding study participation were to be excluded. Given the research questions of the project as a whole, power calculations took the intended longitudinal design into account including comparisons between the three patient groups. Assuming a small effect size $f=0.1$, a type 1 error of 0.01 , power $(1-\beta)$ of 0.80 and a drop-out of $25 \%$ resulted in a suggested sample size of 512 participants that should also be sufficient for the analyses reported here.

Local research coordinators (physician, study nurse, or the like) at the collaborating centers informed eligible patients about the study and asked for a written consent. Having consented, participants completed a questionnaire booklet at each of the three specified measurement points. This booklet included the PCQ-57 as well as established measures of, e.g., coping with cancer, self-efficacy for coping with cancer, fear of progression, and depression.

\section{Measures}

\section{Patient competence}

As a measure of PC, the PCQ-57 includes 57 items [23]. Thirty-five of these describe problem-focused behaviors in the context of the diagnosis, treatment, and survivorship of cancer; the remaining 22 similarly address emotion-focused behaviors (cf. Tables 2 and 3). In pilot surveys, these behaviors had been rated as indicators of PC by cancer patients and psychosocial oncology experts [23]. Problem-focused items cover (a) information-seeking behaviors on diagnosis- and treatment-related topics, (b) communication with physicians, and (c) regulating one's well-being and social relationships. Emotion-focused items represent behaviors aimed at dealing with emotional distress in the cancer context (see supplement S1 for item wordings). All PCQ items are answered on 5-point scales ranging from 1 (not at all true) to 5 (completely true). The emotion-focused competence items offer the additional response option "not applicable" to accommodate the 
possibility that a specific item may not fit the participant's individual situation. Also different from problem-focused items, emotion-focused items have to be responded to with respect to the past 7 days to capture short-term variations that may occur when confronting emotion-focused tasks of cancer and its treatment. Averaging individual item responses, the problem-focused competence items yield five different scale scores: seeking information (8 items), self-regulation (11), assertively interacting with physicians (7), striving for autonomous decisions (7), and interest in social services (2). Similarly, from the emotion-focused items, three scale scores are derived that measure managing distress (10 items), dealing explicitly with the threat to life posed by cancer (6), and low avoidance (6). High scale scores reflect a higher self-rated competence regarding the respective behavioral domain. It should be noted, however, that in the case of the low avoidance scale a high score actually reflects the ability not to make use of avoidant behaviors. The internal consistencies (Cronbach's $\alpha$ ) of the scales range from 0.64 to 0.87 [23]. Scale correlations with criteria that might be taken as preliminary indicators of concurrent validity have already been mentioned in the introductory section.

\section{Coping}

Coping was measured with the Trier Scales of Coping (TSK) that include 37 items describing various coping behaviors [38]. Each behavior is to be rated on a 6-point scale with respect to how often it has been performed within the past weeks. Item responses are summed to give five scale scores addressing rumination, searching for affiliation, minimizing threat, searching for information and social exchange, and searching for meaning in religion, respectively. Higher scores indicate that the respective coping behaviors have been performed more frequently during the previous weeks, Cronbach's $\alpha$ of these scales range from 0.74 to 0.88 . Scale development rests on confirmatory factor analysis in cancer patients $(N=322)$. Structural invariance of the measurement model was confirmed for patients with ankylosing spondylitis $(n=110)$. Significant medium-sized correlations $(|\mathrm{r}| \leq 0.51)$ of specific scales with different measures of stress management in smaller samples $(n \leq 117)$ suggest convergent validity [38].

\section{Self-efficacy for coping with cancer}

Self-efficacy for coping with cancer was measured with the German version of the brief form of the Cancer Behavior Inventory (CBI-B-D [39]). In its currently available version, it includes the 14 items of the American short form of this instrument (CBI-B) that had later been reduced to 12 of these items, however [11]. In order to make CBI results of the present study comparable with the now established American 12-item version, the sum scores computed here are based on the 12 items of the now reduced American version. All items describe coping behaviors to be rated on a 9-point scale from 1 (not at all confident) to 9 (completely confident) with respect to how confident one feels being able to perform the behavior in question. Higher scores indicate higher coping self-efficacy. Internal consistencies are reported to be around 0.84 [11]. Across different samples, positive correlations of the CBI-B with, e.g., measures of quality of life, optimism, and satisfaction with life, and negative ones with measures of fatigue or sickness impact speak to the validity of this measure [11].

\section{Fear of progression}

Fear of progression was measured with the short form of the Fear of Progression Inventory (FoP-Q-SF) [40]. It asks respondents to answer 12 items addressing various fears regarding the progression or relapse of a chronic life-threatening disease like cancer. The items are to be rated on a 5-point scale from never (1) to very often (5) with respect to how often each fear is experienced by the respondent. Higher scores indicate higher fear of progression. Internal consistencies are usually reported to range above 0.80 [40, 41]. Significant differences in means between groups differing by, e.g., disease stages $(p<0.001$, $d=0.61$ ) and large correlations with concurrent measures of anxiety and depression ( 0.71 and 0.57 , respectively) support the validity of the FoP-Q-SF [41].

\section{Depression}

Depression was measured with the PHQ-9, the German version of the depression screening module of the Patient Health Questionnaire [42]. It includes 9 symptoms of depression that are to be rated according to how often they have been experienced during the previous 2 weeks. The response scale ranges from 0 (not at all) to 3 (almost every day). Summing across symptoms yields a scale score that may range from 0 to 27 . Higher scores indicate greater depression. Internal consistencies are usually reported to lie within the range of 0.88 . With respect to detecting major depression, values for sensitivity and specificity of $95 \%$ and $86 \%$, respectively, point to the criterion validity of the instrument.

\section{Sociodemographic and medical characteristics}

A final questionnaire section asked patients to provide information on selected sociodemographic characteristics. Illnessand treatment-related data were obtained from patients' medical records at the collaborating centers. 


\section{Data analysis}

Descriptive statistics were computed for sociodemographic and medical variables. As the overall project asked whether PC might differ by tumor entity, we compared patients on these variables by tumor site using $\chi^{2}$-techniques or ANOVAs and $\phi$ or $\eta^{2}$ as effect size measures. To evaluate the factor structure of the PCQ-57 and the internal consistency of its scales, factor analyses and item analyses based on the socalled classical test theory were computed which assumes an observed test score to be a composite of an individuals' unobservable "true score" and a random error component. Problem-focused and emotion-focused items were factored separately as in the original study [23] since they are rated with respect to different time frames and under a different response format as described above. Given the still exploratory status of research on PC, we deliberately chose to employ exploratory principal axis factor analysis followed by orthogonal varimax rotation in both cases. While carefully considering the course of eigenvalues in both these analyses, we eventually extracted 5 and 3 factors for the problem- and the emotion-focused item set respectively, as in the original analyses [23]. The sample size suggested by the overall power calculations may be considered sufficient to achieve a person to variable ratio of at least 5:1 which is frequently recommended for factor analysis [43, 44]. Missing values were not imputed. Instead, factor analyses were performed with listwise deletion of cases with missing values in a respective item set. Interpretation of factors was guided by the size of its item loadings $\left(a_{i j} \geq 0.60\right)$ and the requirement that the squared loading of an item should account for at least $50 \%$ of the communality of this item $\left(a_{i j}{ }^{2} / h_{i .}{ }^{2} \geq 0.50\right)[44,45]$. To judge whether item inter-correlations were appropriate for factor analysis, the Kaiser-Meyer-Olkin (KMO) measure of sampling adequacy was computed [46] which indicates the proportion of variance in a set that might be explained by underlying factors. With a possible range from 0 to 1 , high $\mathrm{KMO}$ values indicate a variable set to be suitable for factor analysis and values higher than 0.80 are generally regarded as "meritorious."

In order to determine the inter-correlations of the original competence scales and their relationships with coping self-efficacy, coping, fear of progression, and depression, Pearson correlations were computed. For the latter two criteria, hierarchical regressions were also computed with coping, self-efficacy, and competencies as predictors. If competencies actually contributed to an effective self-regulation of distressing emotions, one would expect negative correlations between these two criteria and positively scored competence scales like seeking information or managing distress, although these must not be mistaken to show a causal effect. All computations were performed with IBM SPSS version 23 .

\section{Results}

\section{Sample}

In total, $N=424$ patients could be recruited, with the proportions of breast, colorectal, and prostate cancer patients being roughly equal (see Table 1). On average, patients were $M=61.5$ years old $(S D=9.5), 85 \%$ of the sample were diagnosed with cancer for their first time and median time since diagnosis was $M d n=10.4$ months (not in Table 1). In many of the sample characteristics in Table 1, diagnostic groups differ significantly, with effect sizes being mostly small (data not shown); however, except for age (breast cancer $M=58.9$ years, $\eta^{2}=$ $0.07)$, time since diagnosis $(M d n=21.1$ months for breast cancer women, $\eta^{2}=0.14$ ), and tumor size (T1: breast cancer $43 \%$, colorectal cancer $10 \%$, prostate cancer $4 \%, \phi=0.57)$.

\section{Factor analyses}

A KMO value of 0.85 indicated the problem-focused items were well-suited for factor analysis that resulted in 10 eigenvalues $>1(8.24,3.33,2.01,1.87,1.55,1.45,1.37,1.18,1.14$, and 1.02). The intended 5-factor varimax solution (Table 2) accounts for $41 \%$ of the variance. As their loadings indicate, these factors are readily interpretable as competencies relating to seeking information (F-1, Table 2), self-regulation (F-2), assertively interacting with physicians (F-3), and interest in social services (F-4). The fifth factor (F-5) is defined by two items that cover interest in complementary medicine. Isolated cross-loadings range from 0.25 to $0.38(M d n=0.31)$. As indicated by superscripts in Table 2, the two items defining factor F-5 as well as some of the items defining factor F-1 in the present analysis had loaded on the factor striving for autonomous decisions in the original factor analysis of the PCQ-57 [23].

With respect to the emotion-focused items, a KMO value of 0.79 suggested they were acceptable for factor analysis. Factor analysis resulted in 6 eigenvalues $>1$ $(5.16,2.72,1.90,1.35,1.11$, and 1.04) with their course favoring a 3-factor solution (Table 3) that accounts for $30 \%$ of the variance. As their loadings show, these (varimax rotated) factors may be interpreted as competencies that cover managing emotional distress in the context of cancer (F-1, Table 2), dealing explicitly with the threat to life posed by cancer (F-2) and low avoidance (F-3). Some items show substantial double-loadings $\left(\left|a_{i j}\right| \geq\right.$ 0.30 ) mostly involving factors F-1 and F-2, or low commonalities $\left(h^{2} \leq 0.20\right)$. Especially factor F-3 is defined by a smaller number of items than might have been expected based on the earlier analysis [23]. 
Table 1 Absolute $(f)$ and relative $(\%)$ frequencies of sociodemographic and medical sample characteristics

\begin{tabular}{|c|c|c|}
\hline Characteristic & $f$ & $\%$ \\
\hline \multicolumn{3}{|l|}{ Tumor diagnosis $(\mathrm{n}=424)$} \\
\hline Breast cancer & 145 & 34 \\
\hline Colorectal cancer & 161 & 38 \\
\hline Prostate cancer & 118 & 28 \\
\hline \multicolumn{3}{|l|}{ Gender $(n=424)$} \\
\hline Female & 225 & 53 \\
\hline Male & 199 & 47 \\
\hline \multicolumn{3}{|l|}{ Marital status $(n=420)$} \\
\hline Single & 29 & 7 \\
\hline Married/Cohabitating & 290 & 69 \\
\hline Divorced/separated & 59 & 14 \\
\hline Widowed & 43 & 10 \\
\hline \multicolumn{3}{|l|}{ Children $(n=420)$} \\
\hline Yes & 350 & 83 \\
\hline No & 70 & 17 \\
\hline \multicolumn{3}{|l|}{ Education $(n=408)$} \\
\hline 9 years & 124 & 30 \\
\hline 10 years & 132 & 32 \\
\hline 12 years & 51 & 13 \\
\hline 13 years & 101 & 25 \\
\hline \multicolumn{3}{|l|}{ Employment $(n=418)$} \\
\hline Yes (full time or other) & 237 & 57 \\
\hline No & 181 & 43 \\
\hline \multicolumn{3}{|l|}{$\mathrm{T}(\mathrm{n}=388)$} \\
\hline $\mathrm{T}_{1}$ & 73 & 19 \\
\hline $\mathrm{T}_{2}$ & 126 & 32 \\
\hline $\mathrm{T}_{3}$ & 142 & 37 \\
\hline $\mathrm{T}_{4}$ & 33 & 8 \\
\hline $\mathrm{X}$ & 14 & 4 \\
\hline \multicolumn{3}{|l|}{$\mathrm{N}(\mathrm{n}=398)$} \\
\hline Negative & 200 & 50 \\
\hline Positive & 168 & 42 \\
\hline $\mathrm{X}$ & 30 & 8 \\
\hline \multicolumn{3}{|c|}{ Primary metastases $(\mathrm{n}=387)$} \\
\hline No & 302 & 78 \\
\hline Yes & 69 & 18 \\
\hline $\mathrm{X}$ & 16 & 4 \\
\hline \multicolumn{3}{|c|}{ Treatment intention $(\mathrm{n}=389)$} \\
\hline Curative & 228 & 59 \\
\hline Palliative & 133 & 34 \\
\hline $\mathrm{X}$ & 28 & 7 \\
\hline
\end{tabular}

\section{Internal consistency and scale inter-correlations}

Except for dealing explicitly with threat and low avoidance, the internal consistencies of the PC scales based on the original scoring keys [23] are above 0.70 with a maximum of 0.88 (Table 4). Correlations between competencies are mostly significant, positive, and low to moderate in size $\left(M d n_{r}=0.24,-0.04 \leq r \leq\right.$ 0.61 ; see Table 4), with the exception of high correlations between seeking information and striving for autonomous decisions and between self-regulation and dealing explicitly with the threat to life posed by cancer $(r \geq 0.50)$, both suggesting some overlap between these respective constructs.

Considering the relationships of PC with other constructs focusing upon cancer patients' resources, the competencies of managing distress, low avoidance, and being assertive with physicians and self-regulation correlate significantly and moderately to highly $(0.35 \leq r \leq 0.58)$ with self-efficacy for coping with cancer (Table 4). Thus, higher competency in these domains co-varies to some degree with higher coping self-efficacy. Similarly, given their significant and moderately high correlations, a higher competency of self-regulation is associated with using coping behaviors like seeking affiliation, minimizing threat, and searching for information and social exchange more frequently. The same is true of competency in seeking information which correlates moderately and significantly with using the coping behaviors of searching for information and social exchange and seeking affiliation more frequently. Furthermore, the emotion-focused competency of managing distress is significantly associated with more frequent use of the coping behaviors seeking social affiliation and minimizing threat. The competency of low avoidance correlates moderately highly and negatively (reflecting its scoring direction) with less use of rumination as a coping behavior. Finally, higher self-efficacy for coping with cancer is significantly associated with more frequent use of seeking affiliation and less frequent use of rumination, and minimizing threat $(|r| \geq 0.34)$.

\section{Correlations with fear of progression and depression}

Table 4 also shows the two emotion-focused competencies of managing distress and low avoidance to correlate significantly, negatively, and moderately with fear of progression and depression $(|r| \geq 0.43)$, that is, higher competency in managing emotional distress and low avoidance are associated with less fear of progression and depression. Similarly, higher self-efficacy for coping with cancer is significantly and strongly associated with less fear of progression and depression $(|r| \geq 0.49)$. In contrast, high rumination, as a coping behavior measured with the TSK [38], is significantly and strongly associated with greater fear of progression $(r=0.50)$ and significantly, but to a lower extent with less depression $(r=0.27)$. The hierarchical regressions (not given in detail here) show managing distress as an independent predictor of less fear of progression $\left(\beta=-0.29\right.$, adj $^{2}=0.45$, each 
Table 2 Varimax-rotated 5-factor solution for problem-focused items of PC in the context of cancer $(n=376)$

\begin{tabular}{|c|c|c|c|c|c|c|}
\hline Item (number and truncated wording) & $\mathrm{F}-1$ & $\mathrm{~F}-2$ & $\mathrm{~F}-3$ & F-4 & F-5 & $h^{2}$ \\
\hline 08 . Took my time to discover best therapy ${ }^{a}$ & 0.78 & & & & & 0.66 \\
\hline 10. Sought information on pros and cons of treatments & 0.71 & & & & & 0.59 \\
\hline 01. Sought information on diagnostic procedures & 0.70 & & & & & 0.53 \\
\hline 04. Prepared for stressful diagnostic procedures & 0.70 & & & & & 0.57 \\
\hline 02. Sought information on side effects & 0.61 & & & & & 0.49 \\
\hline 03. Sought information from brochures etc. & 0.61 & & & & & 0.40 \\
\hline 09. Made the right decision for me ${ }^{a}$ & 0.59 & & 0.32 & & & 0.48 \\
\hline 06. Asked how treatments would work & 0.47 & & 0.34 & & & 0.43 \\
\hline 05. Sought information on preventing side effects & 0.46 & & & 0.34 & 0.38 & 0.51 \\
\hline 11. Sought second opinion ${ }^{a}$ & 0.43 & & & & & 0.24 \\
\hline 51. Sought information on how to cope & 0.31 & 0.29 & & & & 0.26 \\
\hline 07. Took measures to minimize side effects & 0.29 & & & 0.36 & 0.43 & 0.45 \\
\hline 12. Doubted physicians' recommendations ${ }^{\text {a }}$ & 0.25 & & & & & 0.14 \\
\hline 13. Left decisions to physicians ${ }^{\text {a }}$ & -0.40 & & & & & 0.19 \\
\hline 48. Try to negotiate how much support I need & & 0.71 & & & & 0.54 \\
\hline 47. Make sure that others help me out & & 0.67 & & & & 0.45 \\
\hline 53. Take care to get rest and relaxation & & 0.64 & & & & 0.44 \\
\hline 52. Take care to get enough sleep & & 0.55 & & & & 0.33 \\
\hline 49. Easy to ask others for support & & 0.54 & & & & 0.33 \\
\hline 50. Feel supported by those close to me & & 0.47 & & & & 0.26 \\
\hline 55. Times of contemplation integrated in my life & & 0.43 & & & & 0.29 \\
\hline 56. Listen to what my body might want to tell me & 0.26 & 0.39 & 0.36 & & & 0.36 \\
\hline 57. Sought information on which activities to avoid & 0.30 & 0.35 & & & & 0.25 \\
\hline 54. Examine my body for changes & & 0.28 & 0.28 & & & 0.26 \\
\hline 22. Ask physician when I do not understand & & & 0.73 & & & 0.60 \\
\hline 23. Successful in asking physician questions & & & 0.65 & & & 0.48 \\
\hline 21. Tell physicians when I'm not content & & & 0.58 & & & 0.37 \\
\hline 20. Get wishes for treatment accepted & 0.25 & & 0.53 & & & 0.39 \\
\hline 19. Tell doctors clearly when I disagree & & & 0.51 & & & 0.29 \\
\hline 18. Find it hard to describe my complaints & & & $-\mathbf{0 . 3 0}$ & & & 0.13 \\
\hline 24. Find it hard to speak my mind & & & -0.31 & & & 0.14 \\
\hline 16. Sought information on financial support & & & & 0.80 & & 0.79 \\
\hline 17. Took efforts to obtain financial support & & & & 0.78 & & 0.64 \\
\hline 14. Sought information on complementary medicine ${ }^{a}$ & 0.27 & & & & 0.73 & 0.62 \\
\hline 15. Contacted specialist in complementary medicine ${ }^{a}$ & & & & & 0.69 & 0.49 \\
\hline
\end{tabular}

Factor loadings in descending order per factor. Only loadings $\left|a_{i j}\right| \geq 0.25$ are printed; loadings with $\left|a_{i j}\right| \geq 0.30$ and $a_{i j}{ }^{2} / h_{\cdot j}{ }^{2} \geq 0.50$ in bold type

${ }^{a}$ Item loading on the factor striving for autonomous decision in the original factor analysis [23] $p<0.01)$ and depression $\left(\beta=-0.24,{ }_{\text {adj }} R^{2}=0.36\right.$, each $p<0.01$ ).

\section{Discussion}

This study examined psychometric properties of the PCQ-57 by analyzing its factor structure, reliability, and validity in terms of its relationships with coping, coping self-efficacy, fear of progression, and depression in a sample of breast, colorectal, and prostate cancer patients. As shown, the competencies of seeking information, self-regulation, assertively interacting with physicians, interest in social services, and managing distress suggested by the original study [23] were rather clearly represented in the factor analyses. Although some items showed double and cross-loadings, these tended to be negligible and do not contradict the interpretation of these five factors. Thus, the factor analyses generally support 
Table 3 Varimax-rotated 3-factor solution for emotion-focused items of PC in the context of cancer $(n=189)$

\begin{tabular}{|c|c|c|c|c|}
\hline Item (number and truncated wording) & F-1 & $\mathrm{F}-2$ & $\mathrm{~F}-3$ & $h^{2}$ \\
\hline 31. Can deal with fears related to disease & 0.74 & & -0.26 & 0.63 \\
\hline 27. Can deal with helplessness & 0.69 & & -0.27 & 0.56 \\
\hline 35. Can deal with the threat caused by illness & 0.68 & & & 0.47 \\
\hline 36. Can deal with physical impairment & 0.62 & & & 0.39 \\
\hline 38. Able to accept feelings like grief & 0.60 & & & 0.39 \\
\hline 32. Can deal with stress of chemotherapy & 0.59 & & & 0.36 \\
\hline 46. Can deal with impaired mobility ${ }^{b}$ & 0.56 & & & 0.33 \\
\hline 41. Able to distract myself when thinking of disease & 0.54 & & & 0.29 \\
\hline 33. Can dismiss thoughts of a possible recurrence & 0.53 & -0.41 & & 0.46 \\
\hline 45. Know how to handle increasing pain ${ }^{b}$ & 0.37 & 0.26 & & 0.20 \\
\hline 34. Hard to accept disease ${ }^{c}$ & -0.47 & & 0.43 & 0.41 \\
\hline 25. Explicitly deal with the possibility of a recurrence & & 0.77 & & 0.60 \\
\hline 26. Consider what disease means to my life & & 0.76 & & 0.61 \\
\hline 43. Consider that I might die & & 0.55 & & 0.31 \\
\hline 44. Try to take good care of myself & 0.32 & 0.36 & & 0.26 \\
\hline 42. Told myself it could be worse ${ }^{a}$ & 0.39 & -0.43 & & 0.37 \\
\hline 29. Confident that all will end well ${ }^{\text {a }}$ & 0.35 & -0.46 & & 0.34 \\
\hline 39. Engage in various activities just to forget & & & 0.52 & 0.28 \\
\hline 37. Do not let others see how I actually feel & & & 0.48 & 0.24 \\
\hline 30. Feel I have to fundamentally change my life & & & 0.43 & 0.21 \\
\hline 28. Difficulty in expressing what I need & & & 0.26 & 0.13 \\
\hline 40. Find consolation in thinking others are worse off than me & & & 0.25 & 0.11 \\
\hline
\end{tabular}

Factor loadings in descending order per factor. Only loadings $\left|a_{i j}\right| \geq 0.25$ are printed; loadings with $\left|a_{i j}\right| \geq 0.30$ and $a_{i j}{ }^{2} / h_{\cdot j}{ }^{2} \geq 0.50$ in bold type

a, b, c Item loading on factors 1, 2, or 3, respectively, of the original factor analysis [23] the multi-dimensional conceptualization of $\mathrm{PC}$ that guided the construction of the PCQ-57. At the same time, these analyses offer only weak support for the competencies of dealing explicitly with the threat to life posed by cancer and low avoidance to be sufficiently clearly represented in the PCQ57 and they fail to identify the competency of striving for autonomous decisions.

The item-analytic results for the PCQ 57 scales mirror those of the factor analyses: competencies that tended to replicate in factor analysis show internal scale consistencies that are either satisfactory or higher compared with competencies that did not. Interestingly, except for low avoidance, the internal consistencies of most scales do not differ markedly from those reported in the original study [23].

Looking at the relationships of PCs with coping behaviors and coping self-efficacy, it appears noteworthy that the problem- and emotion-focused competencies measured with the PCQ-57 correlate mostly moderately highly with measures of coping and coping self-efficacy. This tends to support the assumption that these constructs share a focus on an individual's resources, while at the same time suggesting that competencies measured with the PCQ-57 may in part capture additional facets of dealing with the challenges of one's cancer diagnosis, treatment and survivorship. If so, this would lend further support to the construct validity of this measure.

Turning to concurrent validity, it is worth noting that the emotion-focused competencies of managing distress and-in spite of its weak internal consistency-low avoidance correlates substantially with fear of progression and depression. This suggests that emotion-focused competencies may in fact play a role in the self-management of emotional distress in cancer patients, thus linking the concept to broader theories of self-regulation $[12,30,36]$. This finding also extends our knowledge of correlates of distressing emotions in cancer for which associations with specific coping behaviors [47] and coping self-efficacy [48] have been demonstrated in recent systematic reviews although some heterogeneity between studies had to be acknowledged. It remains to be seen, however, whether PCs will provide a unique contribution to the prediction and explanation of fear of progression or depression. Also, and similar to the fields of coping and coping selfefficacy, testing directional effects of PC on emotion-related cancer outcomes will require further research using longitudinal designs [47, 48].

That most items defining the previous factor striving for autonomous decision [23] now load on seeking information 


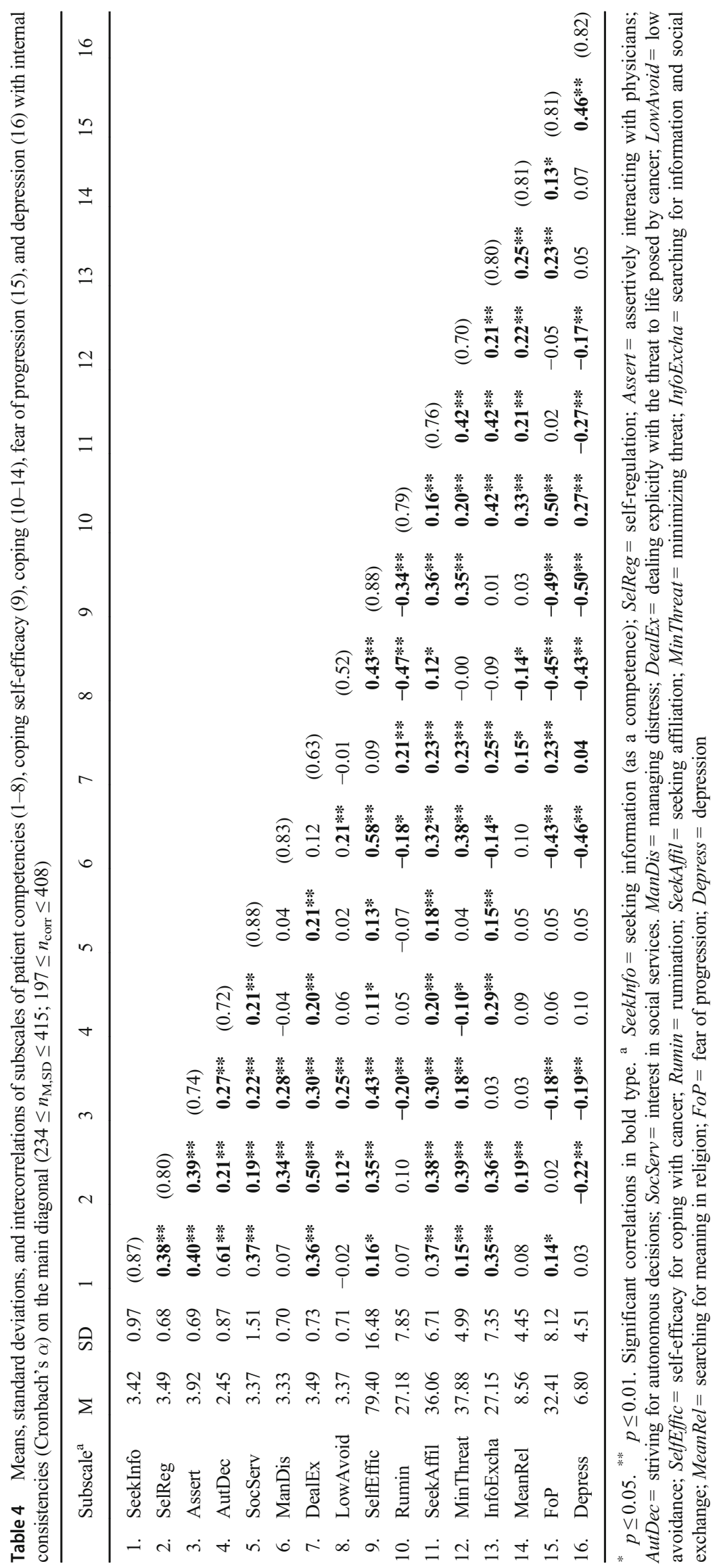


represents the least expected finding of this study. It may reflect a sample bias as the present study includes higher percentages of male, colorectal and prostate cancer patients than the questionnaire construction sample [23] and no patients from acute inpatient or follow-up care. However, the partial fusion of these previously distinct factors in this study that also is mirrored in high scale correlations and similar to the original study [23] may also indicate a reciprocal relationship between seeking information and striving for autonomous decision, that is, acquiring information may facilitate autonomous decisions, while striving for autonomy may in turn motivate information seeking.

\section{Limitations}

While the large sample size, the multi-center recruitment, and the comprehensive validity analyses of the PCQ-57 scales in a network of relevant psycho-oncological constructs represent strengths of this study, there are also some limitations. Firstly, the majority of the participants came from rehabilitation clinics, while patients from other settings of cancer care were less well represented. Secondly, the study included only three different tumor entities, thus restricting generalization of the results. Thirdly, it is difficult to determine the extent of a possible selection bias because the return rate has not been documented. Lastly, analyses at the subgroup level of, e.g., tumor sites would have provided further information, but were not carried out here because of the comparatively smaller sample sizes that would have resulted at this level.

\section{Conclusions}

Summing up then, this study suggests that the PCQ-57 provides a reliable and valid measure of 5 distinct dimensions of PC in the context of cancer as intended: seeking information, self-regulation, assertively interacting with physicians, interest in social services, and managing distress. Their corresponding scales may be useful for evaluating cancer patients' personal resources for confronting emotional distress and specific coping tasks arising from cancer and its treatment. Especially managing distress may represent a scale covering skills that may help reduce distress. These 5 scales also may help identify which competencies a patient may need to develop. In addition, they may be used for research on factors that might influence PC and on effects that PC may have on quality of life, emotional distress, and other cancer outcomes. The extent to which these scales may also help evaluate effects of interventions aimed at promoting PC $[32,33]$ clearly needs to be determined by further research, however. Finally, with respect to those 3 of the 8 PCQ- 57 scales for which no strong support was found in the present analyses, it may be possible to retain striving for autonomous decisions after careful revision, while perhaps omitting dealing explicitly with the threat to life and low avoidance from the instrument. Given the currently renewed and intensified interest in health literacy in cancer [21, 22], another important task of future research will probably be clarifying its conceptual and empirical relationships with other frequently invoked resource constructs like empowerment, patient activation, or PC, and their contributions to psychosocial cancer outcomes.

Acknowledgments We thank the patients and survivors who participated in this study as well as the following Medical Directors and physicians who made this multi-center research possible at their respective rehabilitation centers or their specialized oncology practices: Dres. G. Adam and C. Zeller, Asklepios Clinic for Oncological Rehabilitation, Triberg; Prof. Dr. H.H. Bartsch, Clinic for Oncological Rehabilitation, Clinic for Tumor Biology, Freiburg; PD Dr. R. Caspari, Paracelsus Clinic by the Lake, Clinic for Oncological Rehabilitation, Bad Gandersheim; Dr. T. Dauelsberg, Winkelwald Clinic, Clinic for Oncological Rehabilitation, Nordrach; Dr. W. Hoffmann, Clinic for Oncological Rehabilitation, Park Therme, Badenweiler; Dres. S. Karcher \& S. Fuxius, Specialized Practice in Oncology, Heidelberg; Dr. R. Kobes-Schrödel, Adelsberg Clinic for Oncological Rehabilitation, Bad Berka; Dr. J. Körber, Nahetal Clinic for Oncological Rehabilitation, Bad Kreuznach; Dres. N. Marschner, M. Zaiss, T. Kirste \& D. Semsek, Specialized Practice in Interdisciplinary Oncology \& Hematology, Freiburg/Br.; Dres. M. Mueller and B. Linz, Outpatient Medical Center for Hematology and Oncology, Offenburg; Dr. H. Schäfer, Wehrawald Clinic, Rehabilitation Center Todtmoos, Todtmoos; PD Dr. J. Teichmann and Dr. C. Fernandes Almeida, Rehabilitation Center Oberharz, Clausthal-Zellerfeld.

Authors' contributions Both authors contributed to the conceptualization of the study design, acquisition, statistical analysis and interpretation of the data, drafting and revising the article, and finally approving the version to be submitted.

Funding Open Access funding provided by Projekt DEAL. This work was supported by Germany's Federal Ministry of Education and Research (Grant No. 01GX1051).

\section{Compliance with ethical standards}

Conflict of interest The authors declare that they have no conflicts of interest.

Ethics approval The study received ethics approval from the Ethics Committee of the University of Freiburg under No. 359/12 and was registered at the German Clinical Trials Register under No. DRKS00004410.

Informed consent Informed consent was obtained from all participants prior to study entry.

Open Access This article is licensed under a Creative Commons Attribution 4.0 International License, which permits use, sharing, adaptation, distribution and reproduction in any medium or format, as long as you give appropriate credit to the original author(s) and the source, provide a link to the Creative Commons licence, and indicate if changes were made. The images or other third party material in this article are included in the article's Creative Commons licence, unless indicated otherwise in a credit line to the material. If material is not included in the article's Creative Commons licence and your intended use is not permitted by statutory regulation or exceeds the permitted use, you will 
need to obtain permission directly from the copyright holder. To view a copy of this licence, visit http://creativecommons.org/licenses/by/4.0/.

\section{References}

1. Holland JC (1992) Psycho-oncology: overview, obstacles and opportunities. Psycho-Oncology 1(1):1-13. https://doi.org/10.1002/ pon. 2960010103

2. Simard S, Thewes B, Humphris G, Dixon M, Hayden C, Mireskandari S, Ozakinci G (2013) Fear of cancer recurrence in adult cancer survivors: a systematic review of quantitative studies. J Cancer Surviv 7(3):300-322. https://doi.org/10.1007/s11764-0130272-Z

3. Smith AB, Sharpe L, Thewes B, Turner J, Gilchrist J, Fardell JE, Girgis A, Tesson S, Descallar J, Bell ML, Beith J, Butow P, Beatty L, Bennett B, Brebach R, Brock C, Butler S, Byrne D, Day S, Diggens J, Fairclough A, Faulkner T, Ftanou M, Grier M, Hill G, Jones T, Kirsten L, McConaghey S, McKinnon S, Mihalopoulos C, Mireskandari S, Musiello T, Penhale J, Pollard A, Rangganadhan A, Scealy M, Scott M, Shih S, Teoh M, Tiller K, Watt P, the ConquerFear Authorship G (2018) Medical, demographic and psychological correlates of fear of cancer recurrence (FCR) morbidity in breast, colorectal and melanoma cancer survivors with probable clinically significant FCR seeking psychological treatment through the ConquerFear study. Support Care Cancer 26(12):4207-4216. https://doi.org/10.1007/s00520-018-4294-y

4. Vehling S, Koch U, Ladehoff N, Schön G, Wegscheider K, Heckl U, Weis J, Mehnert A (2012) Prevalence of affective and anxiety disorders in cancer: systematic literature review and meta-analysis (Prävalenz affektiver und Angststörungen bei Krebs: Systematischer Literaturreview und Metaanalyse). Psychother Psychosom Med Psychol 62(7):249-258. https://doi.org/10.1055/ s-0032-1309032

5. Mehnert A, Vehling S, Scheffold K, Ladehoff N, Schön G, Wegscheider K, Heckl U, Weis J, Koch U (2013) Prevalence of adjustment disorder, acute and posttraumatic stress disorders as well as somatoform disorders in cancer patients (Prävalenz von Anpassungsstörung, Akuter und Posttraumati-scher Belastungsstörung sowie somatoformen Störungen bei Krebspatienten). Psychother Psychosom Med Psychol 63(12): 466-472. https://doi.org/10.1055/s-0033-1347197

6. Gattellari M, Voigt KJ, Butow PN, Tattersall MHN (2002) When the treatment goal is not cure: are cancer patients equipped to make informed decisions? J Clin Oncol 20(2):503-513. https://doi.org/ 10.1200/JCO.2002.20.2.503

7. Kane HL, Halpern MT, Squiers LB, Treiman KA, McCormack LA (2014) Implementing and evaluating shared decision making in oncology practice. CA Cancer J Clin 64(6):377-388. https://doi. org/10.3322/caac. 21245

8. Kashaf MS, McGill E (2015) Does shared decision making in cancer treatment improve quality of life? A systematic literature review. Med Decis Mak 35(8):1037-1048. https://doi.org/10.1177/ 0272989X15598529

9. Rowland JH, Kent EE, Forsythe LP, Loge JH, Hjorth L, Glaser A, Mattioli V, Fossa SD (2013) Cancer survivorship research in Europe and the United States: where have we been, where are we going, and what can we learn from each other? Cancer 119(Suppl 11):2094-2108. https://doi.org/10.1002/cncr.28060

10. Kiserud CE, Dahl AA, Fosså SD (2018) Cancer survivorship in adults. In: Goerling U, Mehnert A (eds) Psycho-oncology. Springer International Publishing, Cham, pp 123-143. https://doi. org/10.1007/978-3-319-64310-6_8
11. Heitzmann CA, Merluzzi TV, Jean-Pierre P, Roscoe JA, Kirsh KL, Passik SD (2011) Assessing self-efficacy for coping with cancer: development and psychometric analysis of the brief version of the cancer behavior inventory (CBI-B). Psychooncology 20(3):302312. https://doi.org/10.1002/pon.1735

12. Merluzzi TV, Philip EJ, Heitzmann Ruhf CA, Liu H, Yang M, Conley CC (2018) Self-efficacy for coping with cancer: revision of the cancer behavior inventory (version 3.0). Psychol Assess 30(4):486-499. https://doi.org/10.1037/pas0000483

13. Aujoulat I, d'Hoore W, Deccache A (2007) Patient empowerment in theory and practice: polysemy or cacophony? Patient Educ Couns 66(1):13-20. https://doi.org/10.1016/j.pec.2006.09.008

14. Groen WG, Kuijpers W, Oldenburg HS, Wouters MW, Aaronson NK, van Harten WH (2015) Empowerment of cancer survivors through information technology: an integrative review. J Med Internet Res 17(11):e270. https://doi.org/10.2196/jmir.4818

15. Eskildsen NB, Joergensen CR, Thomsen TG, Ross L, Dietz SM, Groenvold M, Johnsen AT (2017) Patient empowerment: a systematic review of questionnaires measuring empowerment in cancer patients. Acta Oncol 56(2):156-165. https://doi.org/10.1080/ 0284186X.2016.1267402

16. McCorkle R, Ercolano E, Lazenby M, Schulman-Green D, Schilling LS, Lorig K, Wagner EH (2011) Self-management: enabling and empowering patients living with cancer as a chronic illness. CA Cancer J Clin 61(1):50-62. https://doi.org/10.3322/ caac. 20093

17. Hibbard JH, Stockard J, Mahoney ER, Tusler M (2004) Development of the patient activation measure (PAM): conceptualizing and measuring activation in patients and consumers. Health Serv Res 39(4p1):1005-1026. https://doi.org/10.1111/j.14756773.2004.00269.x

18. Hibbard JH, Mahoney E, Sonet E (2017) Does patient activation level affect the cancer patient journey? Patient Educ Couns 100(7): 1276-1279. https://doi.org/10.1016/j.pec.2017.03.019

19. Sorensen K, Van den Broucke S, Fullam J, Doyle G, Pelikan J, Slonska Z, Brand H, Consortium Health Literacy Project European (2012) Health literacy and public health: a systematic review and integration of definitions and models. BMC Public Health 12:80. https://doi.org/10.1186/1471-2458-12-80

20. Osborne RH, Batterham RW, Elsworth GR, Hawkins M, Buchbinder R (2013) The grounded psychometric development and initial validation of the health literacy questionnaire (HLQ). BMC Public Health 13:658. https://doi.org/10.1186/1471-2458$13-658$

21. Altin SV, Halbach S, Ernstmann N, Stock S (2015) How can we measure cancer literacy?-a systematic review on the quality of available measurement tools. Z Evid Fortbild Qual Gesundhwes 109(6):466-482. https://doi.org/10.1016/j.zefq.2015.06.006

22. Goodwin BC, March S, Zajdlewicz L, Osborne RH, Dunn J, Chambers SK (2018) Health literacy and the health status of men with prostate cancer. Psychooncology 27(10):2374-2381. https:// doi.org/10.1002/pon.4834

23. Giesler JM, Weis J (2008) Developing a self-rating measure of patient competence in the context of oncology: a multi-center study. Psychooncology 17(11):1089-1099. https://doi.org/10.1002/pon. 1330

24. Weis J, Giesler JM (2008) Subjective dimensions of patient competence: relationships with selected healthcare usage behaviors and general features of self-rated competence. Patient Educ Couns 73(3):511-518. https://doi.org/10.1016/j.pec.2008.07.010

25. Kösters W (2000) Self-help in action. Becoming a successful patient. Lambertus, Freiburg/Br

26. Rogers A, Kennedy A, Bower P, Gardner C, Gately C, Lee V, Reeves D, Richardson G (2008) The United Kingdom expert patients programme: results and implications from a national evaluation. Med J Aust 189(10 Suppl):S21-S24 
27. Hoffman B, Stovall E (2006) Survivorship perspectives and advocacy. J Clin Oncol 24(32):5154-5159. https://doi.org/10.1200/jco. 2006.06.5300

28. Federal Ministry of Health (2017) National Cancer Plan. Fields of action, goals, recommendations for implementation and results. Federal Ministry of Health, Bonn

29. Lazarus RS (1993) Coping theory and research: past, present, and future. Psychosom Med 55(3):234-247

30. Folkman S, Greer S (2000) Promoting psychological well-being in the face of serious illness: when theory, research and practice inform each other. Psychooncology 9(1):11-19

31. Giesler JM, Keller B, Repke T, Leonhart R, Weis J, Muckelbauer R, Rieckmann N, Muller-Nordhorn J, Lucius-Hoene G, Holmberg C (2017) Effect of a website that presents patients' experiences on self-efficacy and patient competence of colorectal cancer patients: web-based randomized controlled trial. J Med Internet Res 19(10): e334. https://doi.org/10.2196/jmir.7639

32. Klafke N, Mahler C, Uhlmann L, von Hagens C, Bentner M, Schneeweiss A, Müller A, Szecsenyi J, Joos S (2018) Effects of a supportive nurse-led program including complementary and integrative medicine (CIM) on quality of life and patient competence in gynecologic cancer patients undergoing chemotherapy - results of a randomized controlled trial. Oncol Res Treat 41:163-164. https:// doi.org/10.1159/000487109

33. Weis JB, Gschwendtner K, Giesler JM, Adams L, Wirtz MA (2019) Psychoeducational group intervention for breast cancer survivors: a non-randomized multi-center pilot study. Support Care Cancer 28:3033-3040. https://doi.org/10.1007/s00520-01905076-6

34. Butow P, Shaw J, Vaccaro L, Sharpe L, Dhillon H, Smith B, PoCo GFCRIG (2019) A research agenda for fear of cancer recurrence: a Delphi study conducted in Australia. Psycho-oncology 28(5):989 996. https://doi.org/10.1002/pon.5048

35. Korsten LHA, Jansen F, de Haan BJF, Sent D, Cuijpers P, Leemans CR, Verdonck-de Leeuw IM (2019) Factors associated with depression over time in head and neck cancer patients: a systematic review. Psychooncology 28(6):1159-1183. https://doi.org/10.1002/ pon.5058

36. Carver CS, Scheier MF (1998) On the self-regulation of behavior. Cambridge University Press, Cambridge. https://doi.org/10.1017/ CBO9781139174794

37. Bitzer EM, Dierks ML, Heine W, Becker P, Vogel H, Beckmann U, Butsch R, Dorning H, Bruggemann S (2009) Empowerment and health literacy in medical rehabilitation - recommendations for strengthening patient education. Rehabilitation 48(4):202-210. https://doi.org/10.1055/s-0029-1231060

38. Klauer T, Filipp SH (1993) The Trier scales of coping with illness. Hogrefe, Göttingen

39. Giesler JM, Reuter K, Weis J (2006) Changes in self-efficacy for coping with cancer during oncological rehabilitation - a study applying the German brief form of the Cencer behavior inventory. In: DRV-Bund (ed) 18. Rehabilitationswissenschaftliches Kolloquium, Münster. Rehabilitationswissenschaftliches Kolloquium, vol 83. Berlin pp 268-269

40. Mehnert A, Herschbach P, Berg P, Henrich G, Koch U (2006) Fear of progression in breast cancer patients-validation of the short form of the Fear of Progression Questionnaire (FoP-Q-SF). Z Psychosom Med Psychother 52(3):274-288

41. Hinz A, Mehnert A, Ernst J, Herschbach P, Schulte T (2015) Fear of progression in patients 6 months after cancer rehabilitation. A validation study of the fear of progression questionnaire FoP-Q-12. Support Care Cancer 23(6):1579-1587. https://doi.org/10.1007/ s00520-014-2516-5

42. Kocalevent RD, Hinz A, Brahler E (2013) Standardization of the depression screener patient health questionnaire (PHQ-9) in the general population. Gen Hosp Psychiatry 35(5):551-555. https:// doi.org/10.1016/j.genhosppsych.2013.04.006

43. Gorsuch RL (1983) Factor analysis, 2nd edn. Erlbaum, Hillsdale

44. MacCallum RC, Widaman KF, Zhang S, Hong S (1999) Sample size in factor analysis. Psychol Methods 4(1):84-99. https://doi.org/ 10.1037/1082-989X.4.1.84

45. Fürntratt E (1969) Determining the number of interpretable common factor in factor analyses of psychological data. Diagnostica 15(2):62-75

46. Kaiser HF, Cerny BA (1977) A study of a measure of sampling adequacy for factor-analytic correlation matrices. Multivar Behav Res 12(1):43-47. https://doi.org/10.1207/s15327906mbr1201_3

47. Morris N, Moghaddam N, Tickle A, Biswas S (2018) The relationship between coping style and psychological distress in people with head and neck cancer: A systematic review. Psychooncology 27(3): 734-747. https://doi.org/10.1002/pon.4509

48. Chirico A, Lucidi F, Merluzzi T, Alivernini F, Laurentiis MD, Botti G, Giordano A (2017) A meta-analytic review of the relationship of cancer coping self-efficacy with distress and quality of life. Oncotarget 8(22):36800-36811

Publisher's note Springer Nature remains neutral with regard to jurisdictional claims in published maps and institutional affiliations. 